\title{
POBREZA E DESIGUALDADE DE RENDA: UMA ANÁLISE PARA A REGIÃO IMEDIATA DE ILHÉUS-ITABUNA, BAHIA, BRASIL
}

\author{
POVERTY AND INCOME INEQUALITY: AN ANALYSIS FOR THE \\ IMMEDIATE REGION OF ILHÉUS-ITABUNA, BAHIA, BRAZIL
}

\author{
Givaldo Correa dos Santos Neto ${ }^{1}$ \\ Monick Midlej do Espírito Santo ${ }^{2}$ \\ Thaís Santos Amaral ${ }^{3}$ \\ Drielle Santos Oliveira Fernandes ${ }^{4}$ \\ Andréa da Silva Gomes ${ }^{5}$ \\ Mônica de Moura Pires ${ }^{6}$
}

\begin{abstract}
Resumo
O presente artigo parte de um novo recorte regional, a Região de Influência Imediata de IlhéusItabuna, a qual engloba 22 municípios, busca verificar se a pobreza, sob a ótica multidimensional, se apresenta de forma distinta entre as áreas rurais e urbanas e se, nos locais onde há maior desigualdade de renda, os indicadores de pobreza são maiores. Como procedimentos metodológicos foram adotados o Índice de Theil-L, o Coeficiente de Williamson e o Índice de Pobreza Multidimensional. Os dados utilizados referem-se às zonas urbanas e rurais da região imediata de Ilhéus-Itabuna, Bahia, a partir dos setores censitários do Censo Demográfico de 2010 do Instituto Brasileiro de Geografia e Estatística. De acordo com os resultados, nota-se que a pobreza está espraiada pela região analisada, porém mais concentrada nas zonas rurais, as quais apresentam maiores índices de pobreza. Por outro lado, nas zonas urbanas, as quais oferecem maior diversidade de serviços superiores, esses índices de pobreza são menores. Nos principais municípios da região estudada, que são Ilhéus e Itabuna, os níveis de desigualdade de renda são mais elevados nas áreas urbanas. O conjunto dos fatores observados evoca a necessidade de reformulação de políticas públicas para a região, especialmente na geração de emprego, melhor distribuição de renda, aumento no nível educacional da população, melhor infraestrutura e melhor oferta de serviços de saúde básica.
\end{abstract}

\footnotetext{
${ }^{1}$ Mestrando em Economia Regional e Políticas Públicas pela Universidade Estadual de Santa Cruz, Ilhéus, BA, Brasil. Email: givaldo.correa@hotmail.com

${ }^{2}$ Mestranda em Economia Regional e Políticas Públicas pela Universidade Estadual de Santa Cruz, Ilhéus, Bahia. E-mail: mmesanto@uesc.br

${ }^{3}$ Mestranda em Economia Regional e Políticas Públicas pela Universidade Estadual de Santa Cruz, Ilhéus, Bahia. E-mail: thaiamarals@gmail.com

${ }^{4}$ Mestranda em Economia Regional e Políticas Públicas pela Universidade Estadual de Santa Cruz, Ilhéus, Bahia. E-mail: drill.oliveira10@hotmail.com

${ }_{5}^{5}$ Doutora em Desenvolvimento Rural pelo Instituto Nacional Agronômico Paris-Grignon, França. Professora plena do Departamento de Ciências Econômicas da Universidade Estadual de Santa Cruz, Ilhéus, Bahia. E-mail: asgomes@uesc.br

${ }^{6}$ Doutora em Economia Rural pela Universidade Federal de Viçosa. Professora plena do Departamento de Ciências Econômicas da Universidade Estadual de Santa Cruz, Ilhéus, Bahia. E-mail: mpires@uesc.br
} 
Palavras-chave: Desenvolvimento Regional. Privação. Concentração de Renda. Rural-Urbano.

\begin{abstract}
This article focuses on a new regional subdivision, the Region of Immediate Influence of IlhéusItabuna consisting of 22 municipalities, and seeks to verify whether poverty, from a multidimensional perspective, occurs differently in rural and urban areas. It also analyzes whether poverty indicators are higher in places with greater income inequality. The adopted methodological procedures were the Theil-L Index, the Williamson Coefficient, and the Multidimensional Poverty Index. The data used refer to the urban and rural areas of the immediate region of Ilhéus-Itabuna, Bahia, from the census sectors of the 2010 Demographic Census of the Brazilian Institute of Geography and Statistics. The results show that poverty is spread across the analyzed region, but is more concentrated in rural areas, which have higher poverty rates. In urban areas, however, which offer greater diversity of superior services, these poverty rates are lower. In the main municipalities of the studied region of Ilhéus and Itabuna, income inequality levels are higher in urban areas. The set of factors observed reveals the need to reformulate public policies for the region, especially in terms of creating jobs improving income distribution, infrastructure, the provision of basic health services, and increasing the educational level of the population.
\end{abstract}

Keywords: Regional Development. Deprivation. Income concentration. Rural-Urban.

\title{
Introdução
}

Dentre os países da América Latina, o Brasil é um dos países mais desenvolvidos, porém com forte desigualdade de renda e pobreza (NERI, 2006). Essa disparidade entre desenvolvimento e pobreza revela desequilíbrios na distribuição de renda que podem ser evidenciados por diversos estudos. O Word Inequality DataBase mostra que, entre os anos de 2001 a 2015, 27,8\% da renda do Brasil eram apropriados por apenas $1 \%$ dos habitantes do país. O estudo demonstra que, entre 189 países analisados, o Brasil ocupa a $9^{\circ}$ posição no ranking global de países mais desiguais do mundo de acordo com relatório de 2018 da Oxfam Brasil. Nesse relatório, mostra-se que o Coeficiente de Gini de renda domiciliar per capita está estagnado, que há desigualdade entre a renda de homens e mulheres, e entre negros e brancos, que há aumento da mortalidade infantil e aumento da pobreza. Tal situação resultou em inúmeros problemas econômicos, serviços básicos inadequados e precários e políticas ineficientes de combate à inflação no período de 1960 a 1995 (NERI, 2006). Esse cenário começa a se transformar a partir de 1994, especialmente com o Plano Real, principalmente nos esforços mais exitosos de combate à inflação, gerando redução da desigualdade e pobreza no país (NERI, 1996; 2006. BARROS et al., 2000; ROCHA, 2003). Assim, os anos 1990 são marcados por intensos debates, em nível nacional, mas também mundial, sobre pobreza e desigualdade, na busca por políticas de melhoria na qualidade de vida e bem-estar social, como instrumento de diminuição das desigualdades sociais. Dessas discussões, surgem análises a respeito da pobreza que abandonam a ótica unidimensional, baseada na renda como modus operandi, para estudá-la sob uma visão mais ampla, a multidimensional.

Sob esse enfoque, a Organização das Nações Unidas (ONU) inicia um estudo inovador em busca de um indicador multidimensional de desenvolvimento e, inserido nesse processo é desenvolvido o Índice de Pobreza Multidimensional (IPM), elaborado pela Oxford Poverty e Human Development Initiative (OPHI), o qual tem sido utilizado desde 2010 como uma ferramenta de análise dos países em relação a essa questão pelo Programa das Nações Unidas para o Desenvolvimento (PNUD). Essa ferramenta investiga a pobreza por meio do grau de privação das pessoas sob três aspectos: educação, qualidade de vida e saúde.

No Brasil, a partir dos anos 2000, se constrói uma nova agenda de inclusão social por meio de políticas públicas e da aplicação de diversos programas sociais, como o Bolsa Família, a fim de gerar à população de "excluídos" condições mínimas de bem-estar, reduzindo as desigualdades sociais, melhorando a qualidade de vida, produzindo assim mudanças no ambiente externo e interno por meio de políticas públicas orientadas pelo crescimento e estabilidade econômica. 
Na Bahia, a Pesquisa Nacional de Amostra de Domicílios (PNAD) e o Relatório de Cenários Prospectivos para a Bahia (2015-2030) revelam que a proporção de pessoas extremamente pobres no estado passou de $10 \%$, em 2007 , para $6,5 \%$, em 2013, e a proporção de pessoas pobres de $21,7 \%$, em 2007, para 10,4\% da população, em 2013 (SEPLAN, 2016). Esses percentuais revelam que em termos estaduais houve uma melhora, porém será que tal situação ocorreu de maneira semelhante em todo o território baiano, ou existem regiões com maior concentração de pobreza que outras na Bahia?

Prates (2016) e Barbosa (2016), ao analisarem a pobreza sob a ótica multidimensional para o território Litoral Sul da Bahia, identificaram que Itabuna e Ilhéus apresentaram os menores índices de pobreza dentre os 26 municípios que compõem esse território. Isso revela que, embora esses dois municípios exerçam a centralidade regional, o desenvolvimento observado no território é concentrado nesses dois, pois nos demais se observa acentuados índices de pobreza.

Partindo dessas questões e traçando-se um novo recorte regional, a Região de Influência Imediata de Ilhéus-Itabuna (RII Ilhéus-Itabuna), a qual engloba 22 municípios, busca-se verificar, para essa região, se a pobreza, sob a ótica multidimensional, se apresenta de forma distinta entre as áreas rurais e urbanas, e se, nos locais onde há maior desigualdade de renda, os indicadores de pobreza são maiores.

Este trabalho é composto por cinco seções, incluindo esta introdução. Na segunda seção, são sintetizados os conceitos importantes sobre pobreza e desigualdade. Na seção três, apresentam-se os métodos aplicados ao estudo para análise da desigualdade de renda e da pobreza, que são: Índice de Pobreza Multidimensional, Coeficiente de Williamson e Índice de Theil. A seção quatro refere-se aos resultados deste trabalho. A quinta e última seção dedica-se às considerações finais acerca do fenômeno estudado.

\section{Pobreza e desigualdade de renda}

A pobreza por muito tempo foi estudada a partir de análises reducionistas (como insuficiência de renda), porém foi-se notando que esse fenômeno guarda relações estreitas com diversos aspectos, além do econômico, como o político, o social e o ambiental, o que desencadeou análises multifacetadas para compreender tal fenômeno. No que tange ao estudo da pobreza sob a ótica multidimensional, autores como Amartya Sen destacam os fatores que geram a existência da pobreza, ressaltando instrumentos capazes de mensurá-la e delineando as características desses indivíduos denominados de pobres (SEN, 2010).

Para Sen (2010), a pobreza é um fenômeno complexo, pois se relaciona com o desenvolvimento, o qual é resultado do que denomina de liberdade, sendo esta condicionada pelas oportunidades sociais, políticas e econômicas. Nesse contexto, surgem inúmeras contribuições sob essa perspectiva multifacetada. Somam-se aqui as contribuições de Alkire (2002), que estabeleceu razões para a necessidade de se atentar a essas dimensões, salientando a multidimensionalidade no desenvolvimento humano e na pobreza, apresentando metodologias capazes de captar toda essa abrangência.

Essa discussão é também apresentada em Rocha (2003), quando questiona a abordagem da pobreza em função da renda, pois tal fato revela a fragilidade dessa perspectiva de análise, já que não consegue dimensioná-la e captá-la em toda sua magnitude, importância e abrangência. Ademais, a autora sintetiza essa discussão a partir do perfil dos pobres no Brasil, em que salienta "[...] aspectos do seu bem-estar não estão diretamente vinculados à renda - como o acesso a serviços básicos -, o que permite inferir diferenciais quanto à condição de vida dos pobres de forma multifacetada" (ROCHA, 2003, p. 143).

Barros, Carvalho e Franco (2006) também contribuem a respeito dessa discussão ao afirmar que as ferramentas da mensuração multidimensional da pobreza são fundamentais para se fazer análises profundas a respeito desse fenômeno e porque são imprescindíveis em avaliações de seu impacto e no delineamento de programas sociais.

Entender como e por que se desenvolvem as regiões têm orientado as pesquisas e os avanços na ciência regional, pois nem sempre os aspectos locacionais da produção e renda são suficientes para explicar a pobreza e as disparidades regionais, muito embora forneçam indicadores orientadores de crescimento. Porém, variáveis que se atenham unicamente a aspectos econômicos, como o PIB, por exemplo, são insuficientes para caracterizar o desenvolvimento de determinada região e, sobretudo, para explicar os motivos pelos quais cidades/regiões se desenvolvem de forma 
distinta. Quando se discute desenvolvimento é necessária a inclusão de aspectos socioeconômicos como escolarização, acesso à saúde, ao saneamento básico, ao emprego, dentre outros.

Em relação à pobreza, essa é resultado de desigualdades de inúmeras formas, como relativas aos direitos ou liberdades, às oportunidades, às condições de vida etc. Neste trabalho, a desigualdade será analisada sob a ótica da renda, pois essa, de certa maneira, exprime e sintetiza a realidade de uma região, além de ser uma variável de fácil mensurabilidade. Barros et al. (2006) salientam que a redução da desigualdade da renda tende a gerar diminuição da pobreza, pois tal diminuição tenderia a fazer com que a renda dos pobres crescesse mais rapidamente que a dos ricos.

De fato, em geral, o impacto do crescimento econômico sobre a pobreza é tão maior quanto menor for a desigualdade na distribuição de renda. Em outras palavras, reduções no grau de desigualdade não apenas têm impacto direto sobre a pobreza, como também elevam a capacidade de o crescimento econômico beneficiar os mais pobres. É evidente que o inverso também é verdadeiro: o crescimento não apenas tem impacto direto sobre a pobreza, como também eleva a capacidade de futuras reduções no grau de desigualdade diminuírem a pobreza (BARROS et al, 2006, p. 349).

Apesar dos avanços de medidas na redução da desigualdade de renda, o Brasil ainda apresenta altos indicadores de concentração e ocupa posição de destaque negativo no cenário internacional por ter um dos maiores níveis de concentração de renda - 95\% dos países que apresentam dados para estimativa de concentração estão em situação melhor que a brasileira (BARROS et al., 2006, p. 22).

Dedecca (2006) destaca que o desafio brasileiro para superação da pobreza requer, ao mesmo tempo, redução da desigualdade e elevação da renda média, daí a necessidade de coadunar políticas de desenvolvimento com políticas sociais.

Estudos sobre a desigualdade de renda na Bahia "evidenciam que, embora o processo de crescimento econômico tenha transformado a economia baiana, tornando seu PIB o sexto e, posteriormente, sétimo do país, ainda não conseguiu reverter o histórico de desigualdades sociais que caracteriza a evolução econômica da Bahia" (GUERRA, 2017, p. 75).

De acordo com Oliveira e Cavalcanti (2013), dada a extensão territorial da Bahia e sua contribuição para economia do Nordeste e do Brasil, analisar esse fenômeno para a Bahia é essencial para compreender a dinâmica de desigualdade de renda também no Brasil. Em suas análises, os autores notaram que, entre 2003 e 2011, os municípios baianos que tiveram maior crescimento do nível educacional médio foram também os que obtiveram os menores índices de desigualdade renda.

Analisando a evolução do índice de Gini total para o Estado da Bahia, segundo Cavalcanti, Silva e Queiroz (2013), nota-se que se apresenta uma série em declínio nos valores obtidos através do cálculo do índice, ou seja, há uma tendência de diminuição da desigualdade de renda, passando de 0,632 em 2001 para 0,574, no ano de 2009, lembrando que os resultados do índice de Gini variam de zero a um, sendo um o grau máximo de desigualdade.

Para Leite et al. (2016) os gaps, ou lacunas de privação, os quais representam a distância entre um determinado limite total de pobreza e os indivíduos pobres, apontam uma diminuição na incidência de privação, o que demonstra um avanço na contração da pobreza em suas várias dimensões na Bahia. Entretanto há ainda uma diferença significativa entre a pobreza do meio rural em relação às áreas urbanas do estado, a qual conduz a construção deste trabalho.

\section{Metodologia}

\section{Área de estudo}

O estudo pauta-se na nova Divisão Regional do Brasil em Regióes Geográficas Imediatas e Regiões Geográficas Intermediárias ${ }^{7}$ do Instituto Brasileiro de Geografia e Estatística (IBGE) de

\footnotetext{
7 Segundo o Instituto, observou-se uma diferenciação interna do território do país como resultado das transformações políticas, ambientais, econômicas e demográficas ao longo das últimas décadas. A respeito da conceituação das regiões, o IBGE define as Regióes Geográficas Imediatas tendo como a rede urbana o seu principal elemento de referência. Elas são estruturadas a partir de centros urbanos próximos que satisfazem as necessidades imediatas da população, tais como: mercado de trabalho, saúde, educação, comércio e serviços públicos diversos. As Regiões Geográficas Intermediárias organizam o território por meio de um polo de hierarquia superior a partir dos fluxos de gestão público e privado e da existência de funções urbanas de maior complexidade. (IBGE, 2017).
} 
2017. Nessa nova divisão, a Bahia é composta por 34 regiões imediatas, sendo a de Ilhéus-Itabuna uma dentre elas, a qual é objeto deste trabalho. A RII Ilhéus-Itabuna (Figura 1) é composta por 22 municípios e 1.115 setores censitários ${ }^{8}$ (714 urbanos e 401 rurais), cerca de 661.396 habitantes para o ano de 2010, ocupando uma área de 10.755,84 km² (IBGE, 2019).

Na região estudada, Ilhéus e Itabuna constituem-se os municípios mais importantes. Itabuna é o município mais populoso (população estimada em 212.740 habitantes para 2018) abrangendo uma área de 401,03 $\mathrm{km}^{2}$ e Ilhéus, com população estimada em 164.844 habitantes para 2018, ocupando uma área de 1.584,69 km², conforme IBGE (2019).

Figura 1: Região de Influência Imediata de Ilhéus-Itabuna, Bahia, Brasil, 2019

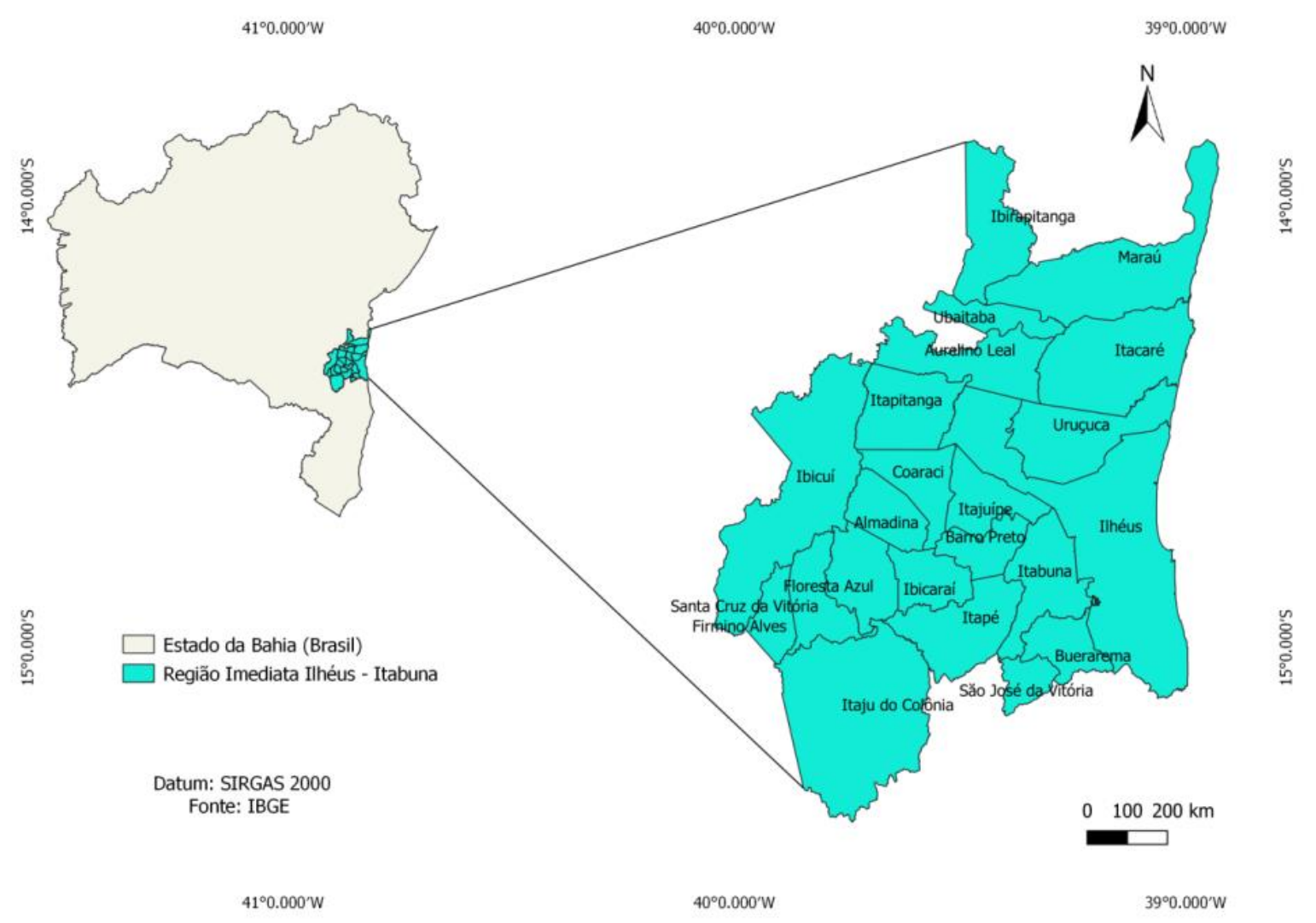

Fonte: IBGE (2017), elaborada pelos autores.

Por setores censitários do IBGE (2010), os municípios da Região de estudo têm população predominantemente urbana $(82,1 \%)$, e a soma da população dos municípios de Ilhéus e Itabuna representa $52,4 \%$ da população urbana total da região. Em Ilhéus, tem-se o maior contingente de população rural (23\%) dentre os 22 municípios, seguido por Ibirapitanga (13,5\%) e Maraú $(12,8 \%)$.

\footnotetext{
${ }^{8}$ Unidade territorial de coleta das operações censitárias, conforme IBGE, com limites físicos identificados, em áreas contínuas e respeitando a divisão político-administrativa do Brasil.
} 
Tabela 1: População da Região Imediata de Ilhéus-Itabuna, Bahia, Brasil, 2010

\begin{tabular}{|c|c|c|c|c|c|}
\hline \multirow{2}{*}{ Município } & \multicolumn{3}{|l|}{ População } & \multicolumn{2}{|l|}{$\%$} \\
\hline & Urbana (a) & Rural (b) & Total (c) & $a / c^{*}$ & $\mathrm{~b} / \mathrm{c}$ \\
\hline Almadina & 5.080 & 1.277 & 6.357 & $80 \%$ & $20 \%$ \\
\hline Aurelino Leal & 11.426 & 2.169 & 13.595 & $84 \%$ & $16 \%$ \\
\hline Barro Preto & 5.295 & 1.158 & 6.453 & $82 \%$ & $18 \%$ \\
\hline Buerarema & 15.277 & 3.328 & 18.605 & $82 \%$ & $18 \%$ \\
\hline Coaraci & 19.130 & 1.834 & 20.964 & $91 \%$ & $9 \%$ \\
\hline Firmino Alves & 4.337 & 1.047 & 5.384 & $81 \%$ & $19 \%$ \\
\hline Floresta Azul & 7.343 & 3.317 & 10.660 & $69 \%$ & $31 \%$ \\
\hline lbicaraí & 17.885 & 6.387 & 24.272 & $74 \%$ & $26 \%$ \\
\hline Ibicuí & 11.964 & 3.821 & 15.785 & $76 \%$ & $24 \%$ \\
\hline lbirapitanga & 6.163 & 16.435 & 22.598 & $27 \%$ & $73 \%$ \\
\hline llhéus** & 156.341 & 27.895 & 184.236 & $85 \%$ & $15 \%$ \\
\hline Itabuna*** & 199.643 & 5.024 & 204.667 & $98 \%$ & $2 \%$ \\
\hline Itacaré & 13.642 & 10.676 & 24.318 & $56 \%$ & $44 \%$ \\
\hline Itajú do Colônia & 5.860 & 1.449 & 7.309 & $80 \%$ & $20 \%$ \\
\hline Itajuípe & 16.839 & 4.242 & 21.081 & $80 \%$ & $20 \%$ \\
\hline Itapé & 7.180 & 3.815 & 10.995 & $65 \%$ & $35 \%$ \\
\hline Itapitanga & 7.591 & 2.616 & 10.207 & $74 \%$ & $26 \%$ \\
\hline Maraú & 3.561 & 15.540 & 19.101 & $19 \%$ & $81 \%$ \\
\hline Santa Cruz da Vitória & 5.076 & 1.597 & 6.673 & $76 \%$ & $24 \%$ \\
\hline São José da Vitória & 5.162 & 553 & 5.715 & $90 \%$ & $10 \%$ \\
\hline Ubaitaba & 17.598 & 3.093 & 20.691 & $85 \%$ & $15 \%$ \\
\hline Uruçuca & 15.779 & 4.058 & 19.837 & $80 \%$ & $20 \%$ \\
\hline Total & 558.172 & 121.331 & 679.503 & $82 \%$ & $18 \%$ \\
\hline
\end{tabular}

\section{Procedimentos de análise}

Para analisar a pobreza e a desigualdade de renda para a região de estudo são utilizados três indicadores: Coeficiente de Williamson, para mensurar os níveis de renda per capita da região na distribuição da renda; Índice de Theil-L, para analisar a desigualdade de renda a partir da renda per capita; Índice de Pobreza Multidimensional, para estimar o nível de privação dos indivíduos e caracterizá-los a partir daí como pobres ou não pobres. Todos os indicadores variam entre 0 (zero) e 1 (um).

A fonte de dados é o Censo Demográfico de 2010 do IBGE, e as análises são feitos por setor censitário do IBGE.

\section{a) Coeficiente de Williamson}

O Coeficiente de Williamson $(\mathrm{CW})$ "[...] mede a dispersão dos níveis da renda regional per capita, relativamente à média nacional, enquanto cada desvio regional é ponderado por sua participação na população nacional” (WILLIAMSON, 1977, p. 67). A partir do cálculo desse coeficiente estima-se a desigualdade da renda entre as áreas urbanas e rurais. $\mathrm{O}$ cálculo é feito da seguinte forma:

$$
C W=\frac{\sqrt{\sum_{i=1} n\left(\frac{Y_{i}}{P_{i}}-\frac{Y}{P}\right)^{2} x \frac{P_{i}}{P}}}{\frac{Y}{P}}
$$

em que, $Y i=$ renda per capita na i-ésima região; $Y=$ renda per capita nacional; $P_{i}=$ população da i-ésima região; $P=$ população nacional.

0 valor do coeficiente varia entre 0 e 1 , quanto mais próximo de 0 menor a desigualdade renda e mais próximo de 1 maior essa desigualdade.

\section{b) Índice de Theil-L}


O Índice de Theil-L é um indicador sintético de aferição de desigualdade de renda. O seu cálculo é feito pelo logaritmo da razão entre a média aritmética da renda per capita (U) e a média geométrica da distribuição de renda $\left(U^{\prime}\right)$ em uma determinada localidade. O logaritmo se dá da seguinte forma:

$$
\text { Índice de TheilL }=\ln U / U^{\prime}
$$

Nesse cálculo divide-se a renda per capita dos setores censitários de cada município em rural e urbano, sendo que, no total das variáveis que compreende o município, cada setor censitário é considerado como um elemento componente do cálculo da média. Em seguida foram calculadas as médias para todos os setores censitários rurais e urbanos por município, e logaritmizado o produto das médias.

No cálculo do coeficiente de Williamson e Índice de Theil-L, foram utilizados os valores do total do rendimento nominal mensal dos homens com idade acima de 10 anos e o total do rendimento nominal mensal das mulheres com idade acima de 10 anos.

\section{c) Índice de Pobreza Multidimensional (IPM)}

O cálculo do IPM foi feito baseando-se em Alkire e Foster (2007; 2009; 2010), o qual é composto por três dimensões: saúde, educação e padrão de vida, conforme disposto na Tabela 2. A adaptação refere-se à disponibilidade de dados para o Brasil, de forma a manter coerência com a proposta inicial dos autores.

Tabela 2: Composição do Índice de Pobreza Multidimensional

\begin{tabular}{|l|l|l|}
\hline Dimensão & $\begin{array}{l}\text { Indicador } \\
\text { (Original) }\end{array}$ & Indicador Utilizado (Adaptação) \\
\hline Saúde & $\begin{array}{l}\text { Nutrição } \\
\text { Mortalidade infantil }\end{array}$ & Capacidade de se alimentar \\
\hline Educação & $\begin{array}{l}\text { Anos de estudo } \\
\text { Frequência de crianças à escola }\end{array}$ & Pessoas não alfabetizadas \\
\hline Padrão de vida & $\begin{array}{l}\text { Combustível para cozinhar } \\
\text { Saneamento }\end{array}$ & $\begin{array}{l}\text { Saneamento } \\
\text { Abastecimento de água } \\
\text { Eletricidade } \\
\text { Coleta de lixo } \\
\text { Aquisição de ativos } \\
\text { Eletricidade } \\
\text { Pavimento } \\
\text { Ativos }\end{array}$ \\
\hline
\end{tabular}

Fonte: Adaptado de Alkire e Santos (2010) e Martins (2018).

Para o primeiro indicador, "capacidade de se alimentar", foi considerado o rendimento per capita dos habitantes dos setores censitários. 0 indicador "pessoas não alfabetizadas" levou em consideração pessoas não alfabetizadas com idade acima de nove anos, tomando-se como referência o disposto no Decreto $\mathrm{n}^{0} 6.094 / 2007$, o qual refere que a alfabetização deve ser concluída até os oito anos de idade. Para os indicadores "saneamento", "abastecimento de água", "eletricidade" e "coleta de lixo", foram observados os domicílios que não têm acesso a esses serviços ou que o acesso é inadequado. A "aquisição de ativos" considerou como referência o salário mínimo nacional para o ano de 2010.

Para o cálculo do IPM, primeiramente elaborou-se uma matriz de realizações (ALKIRE; SANTOS, 2010) que mostra o indivíduo por dimensão. Posteriormente, tem-se a matriz de privações, por meio da identificação dos indivíduos privados em quaisquer dos indicadores utilizados.

Partindo-se dessa matriz, fez-se um segundo corte considerando a pontuação de privação igual ou maior ao corte da pobreza adotado, no caso 0,33 (resultante da razão 1/3, uma vez que o IPM varia entre 0-1 e são utilizadas três dimensões, conforme Tabela 2). 0 indivíduo que apresentar ao menos $30 \%$ de privação é considerado multidimensionalmente pobre, excluindo-se todos os demais indivíduos (ALKIRE; SANTOS, 2010).

Assim, obtém-se a segunda matriz contendo apenas os indivíduos multidimensionalmente pobres, e a partir daí calcula-se a medida de pobreza $(M o)$ representada pela soma ponderada das privações dos pobres, dividida pela multiplicação entre número total de indivíduos (n) e o número total de indicadores considerados (d) (ALKIRE; SANTOS, 2010): 


$$
M o=\sum_{i=1}^{n} \sum_{j=1}^{d} g_{i j}^{0} / n d
$$

em que $\sum_{j=1}^{d} g_{i j}^{0}$ representa a soma das privações ponderadas vividas pelas pessoas (i) no indicador (j) (PRATES, 2016).

O IPM pode também ser mensurado pelo produto da intensidade $(A)$ e incidência $(H)$ da pobreza (ALKIRE; SANTOS, 2010). A intensidade da pobreza é dada por:

$$
A=\sum_{i=1}^{n} C_{i}(K) / d q
$$

Para se obter A, Alkire e Santos (2010) recomendam obter a fração de indicadores ponderados, em que a pessoa pobre $i$ é privada $C i(K) / d$. Nesse caso, $A$ é a média da fração dos indivíduos pobres $(q)$.

Para a incidência da pobreza $(H)$, calcula-se a razão entre o número de pobres $(q)$ e o total de indivíduos $(n)$ :

$H=q / n$

Após esses cálculos, chega-se ao IPM, o qual é obtido pela multiplicação entre $A$ e $H$ :

$I P M=A \times H$

O valor do IPM varia entre 0 a 1 . Quanto mais próximo de 1 , maior é a pobreza sob a ótica multidimensional, quanto menor que 1 , menor é essa pobreza.

\section{Resultados e discussão}

\section{Desigualdade de renda na região de influência imediata (RII) Ilhéus-Itabuna}

De acordo com os resultados, nota-se que a desigualdade de renda, medida pelo Coeficiente de Williamson (CW), é mais elevada nos municípios mais urbanizados da RII Ilhéus-Itabuna (Figuras 2 e 3$)$.

Em relação aos setores censitários rurais, não se observam grandes disparidades entre os municípios, entretanto Ilhéus apresenta o maior coeficiente de desigualdade de renda, Figuras 2a. Dentre os municípios que compõem a região de estudo, Ilhéus tem a maior população rural e também a maior extensão territorial rural (quase metade dessa extensão é classificada como rural). No setor censitário urbano, Itabuna e Ilhéus apresentam os maiores coeficientes de desigualdade de renda (Figura 2b), CW de aproximadamente 0,50 e 0,44, respectivamente.

Figura 2: Coeficiente de Williamson (CW) por setor censitário rural (a) e urbano (b), RII IlhéusItabuna, 2010
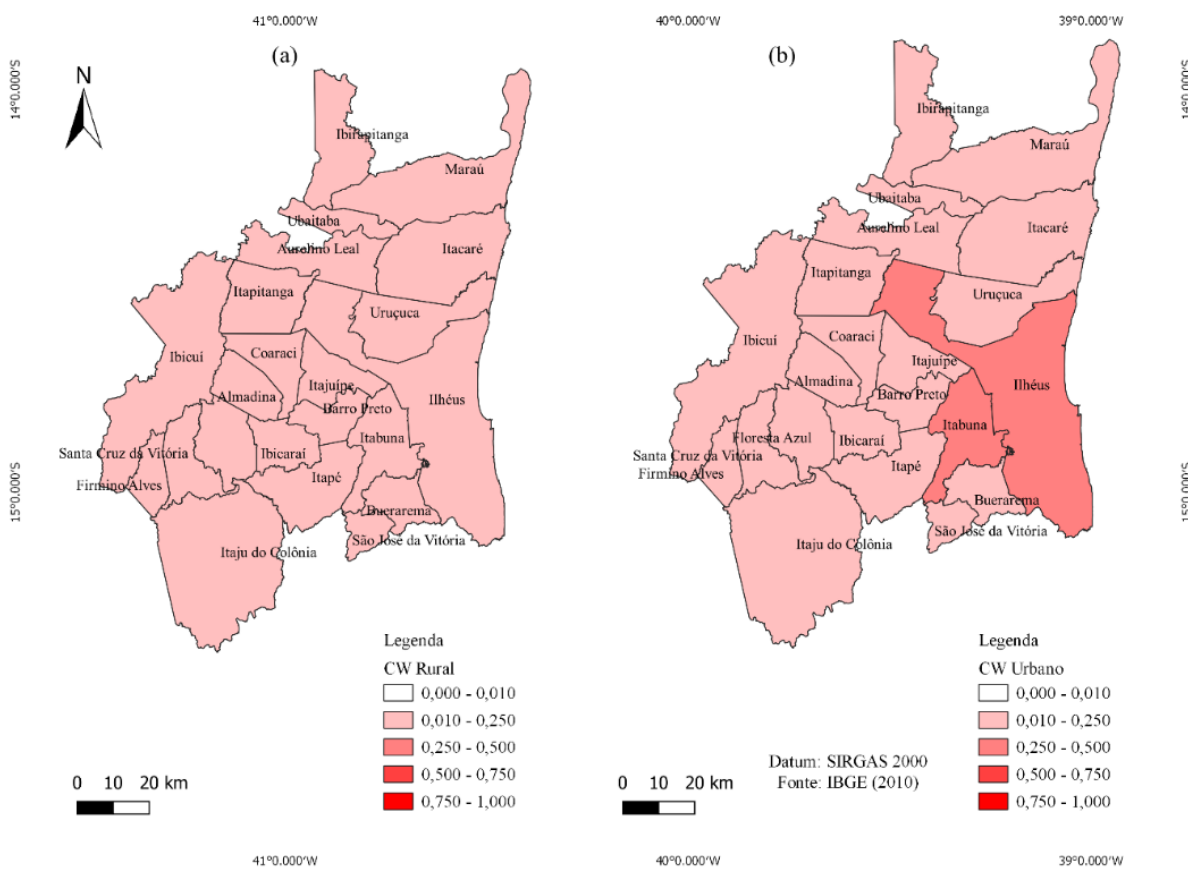

Fonte: Elaborada pelos autores. 
Figura 3: Coeficiente de Williamson (CW) dos municípios da RII Ilhéus-Itabuna, 2010

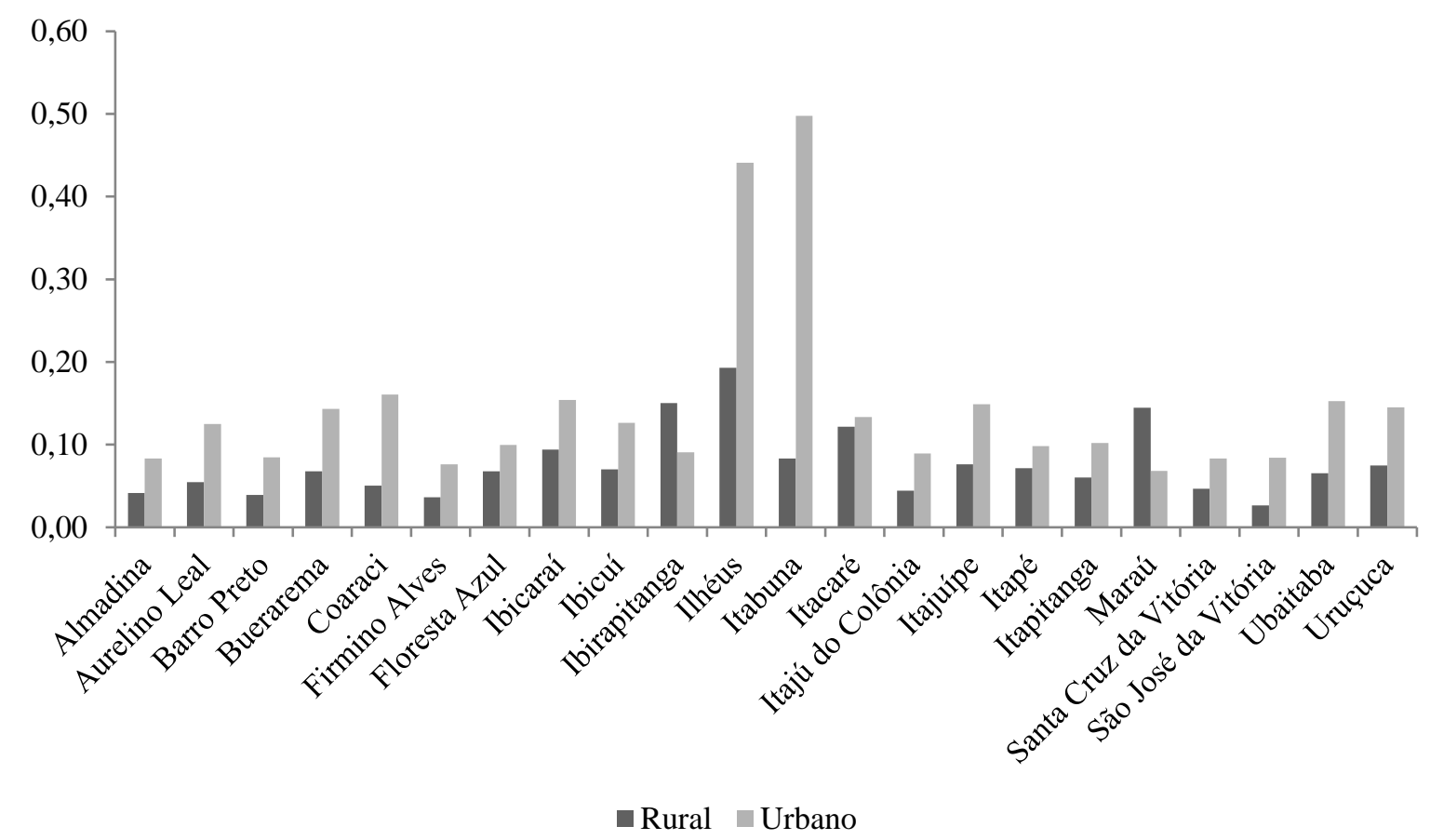

Fonte: IBGE (2010), elaborado pelos autores.

Diversos são os fatores que podem influenciar nesse quadro regional, especialmente relacionados à deficiência na oferta de serviços públicos essenciais como educação, saúde, transporte, saneamento, infraestrutura, oportunidade de emprego, os quais podem levar a população a não ter acesso a uma maior remuneração no mercado de trabalho. Destarte, na ausência de políticas que interrompam esse círculo vicioso, reproduz-se um quadro grave de desigualdade e pobreza, mais evidente ainda nas zonas rurais, onde o acesso é mais precário àqueles tipos de serviços.

Além disso, a crise na lavoura cacaueira nos anos 1990 gerou forte migração rural-urbana nos municípios de Ilhéus e Itabuna (MARTINS, 2018), os quais como locais-centros da RII estudada, acabou recebendo maior contingente de migrantes dos municípios produtores de cacau. Com isso, conforme assinala Santos et al. (2010), se alterou substancialmente a estrutura econômica e social local, agravou o déficit habitacional e permitiu o crescimento da favelização, subempregos para alocar a mão de obra rural nas cidades e falta de capacidade de suporte infraestrutural para acolher esses migrantes.

Pari passu a essa desigualdade de renda e a pobreza, dadas as privações enfrentadas pela população, houve também aumento da criminalidade, em que o município de Itabuna se posiciona como um dos mais violentas no Brasil, com taxa de homicídio em quase $70 \%$ no de 2010, último censo demográfico produzido no país, segundo o IPEA (2018).

Para a região estudada, dados do IPEA (2018) ressaltam que em Itabuna, também no ano de $2010,58,2 \%$ das crianças encontram-se em situação de vulnerabilidade em relação à pobreza, $28 \%$ dos jovens de 18 a 24 anos se encontram sem ocupação formal e 15,4\% dos jovens de 15 a 24 anos nem trabalham e nem estudam, e também se encontram vulneráveis à pobreza. Tal fato já se constituía em realidade, de acordo com os dados de 2010 do Índice de Pobreza Multidimensional (IPM) médio dos municípios (Figura 4). De maneira geral, observa-se que a situação de pobreza é mais grave nas zonas rurais (Figura 4a) comparativamente às zonas urbanas (Figura 4b). 
Figura 4: IPM médio por setor censitário rural (a) e urbano (b) para os municípios da RII IlhéusItabuna, 2010
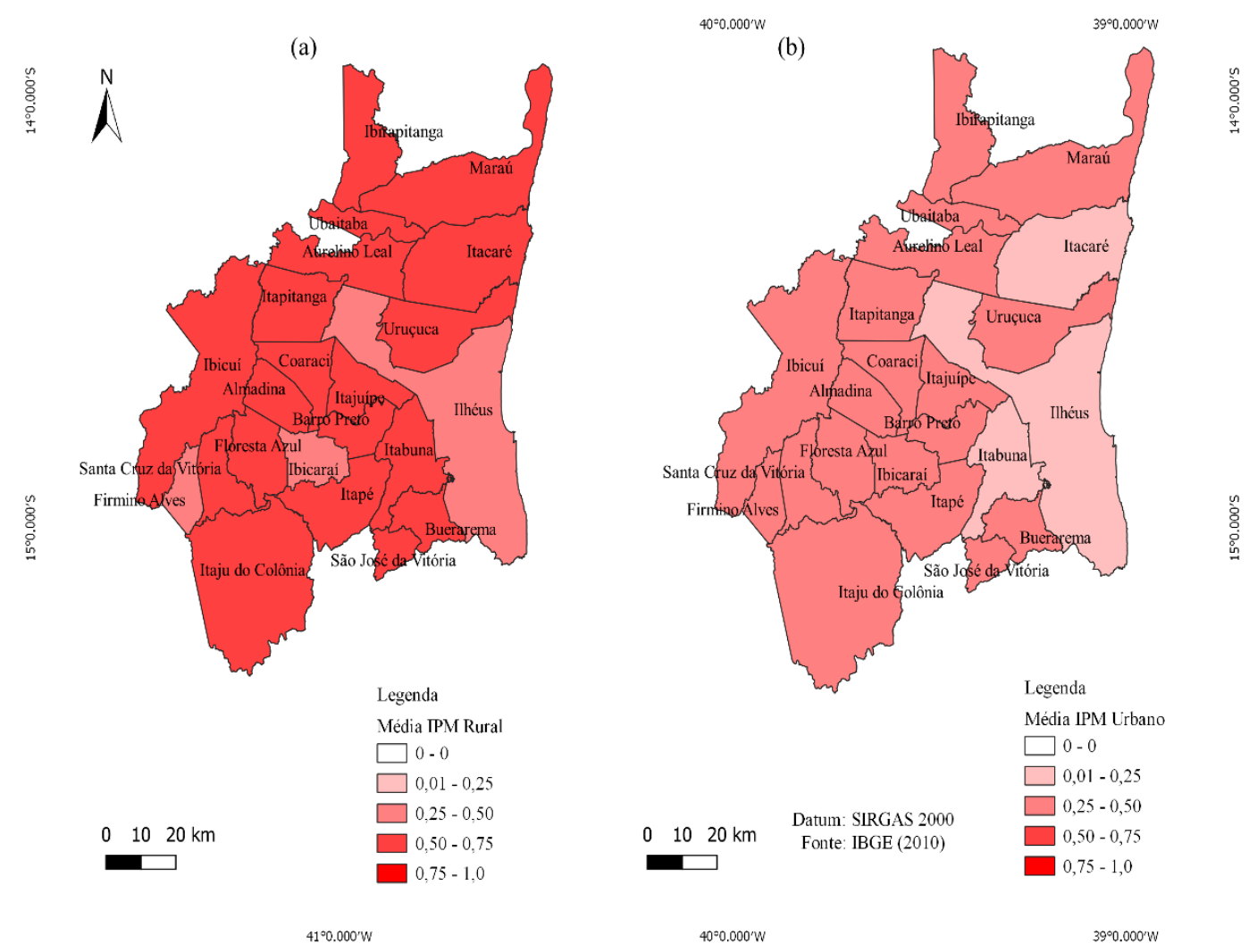

Fonte: Elaborada pelos autores.

Além disso, os IPM corroboram com resultados obtidos para o $\mathrm{CW}$, e novamente nas zonas urbanas de Ilhéus e Itabuna encontram-se os menores índices de privação, porém maior desigualdade de renda (Figuras 3 e 4). Ademais, os municípios Maraú, Ibirapitanga, Itacaré, São José da Vitória, Aurelino Leal e Itajú do Colônia apresentam elevada pobreza nas áreas rurais, revelando fortes disparidades regionais.

Essa incapacidade monetária da população em adquirir ativos revelada pelo IPM reflete a desigualdade e concentração da renda, e consequentemente a ausência de políticas públicas para fomentar empregos e ofertar serviços adequados de esgotamento sanitário e abastecimento de água nesses municípios.

Ao aplicar o Índice de Theil-L, notam-se resultados semelhantes ao Coeficiente de Williamson para os setores censitários urbanos, em que Itabuna e Ilhéus apresentam acentuada concentração de renda, e Ilhéus com concentração na zona rural. Para o Índice de Theil, o valor médio da RII foi 0,09 , e novamente Itabuna e Ilhéus apresentam os maiores coeficientes de desigualdade nas zonas urbanas, 0,22 e 0,21 , respectivamente. 
Figura 5: Índice de Theil-L por setor censitário rural e urbano para a RII Ilhéus-Itabuna, 2010

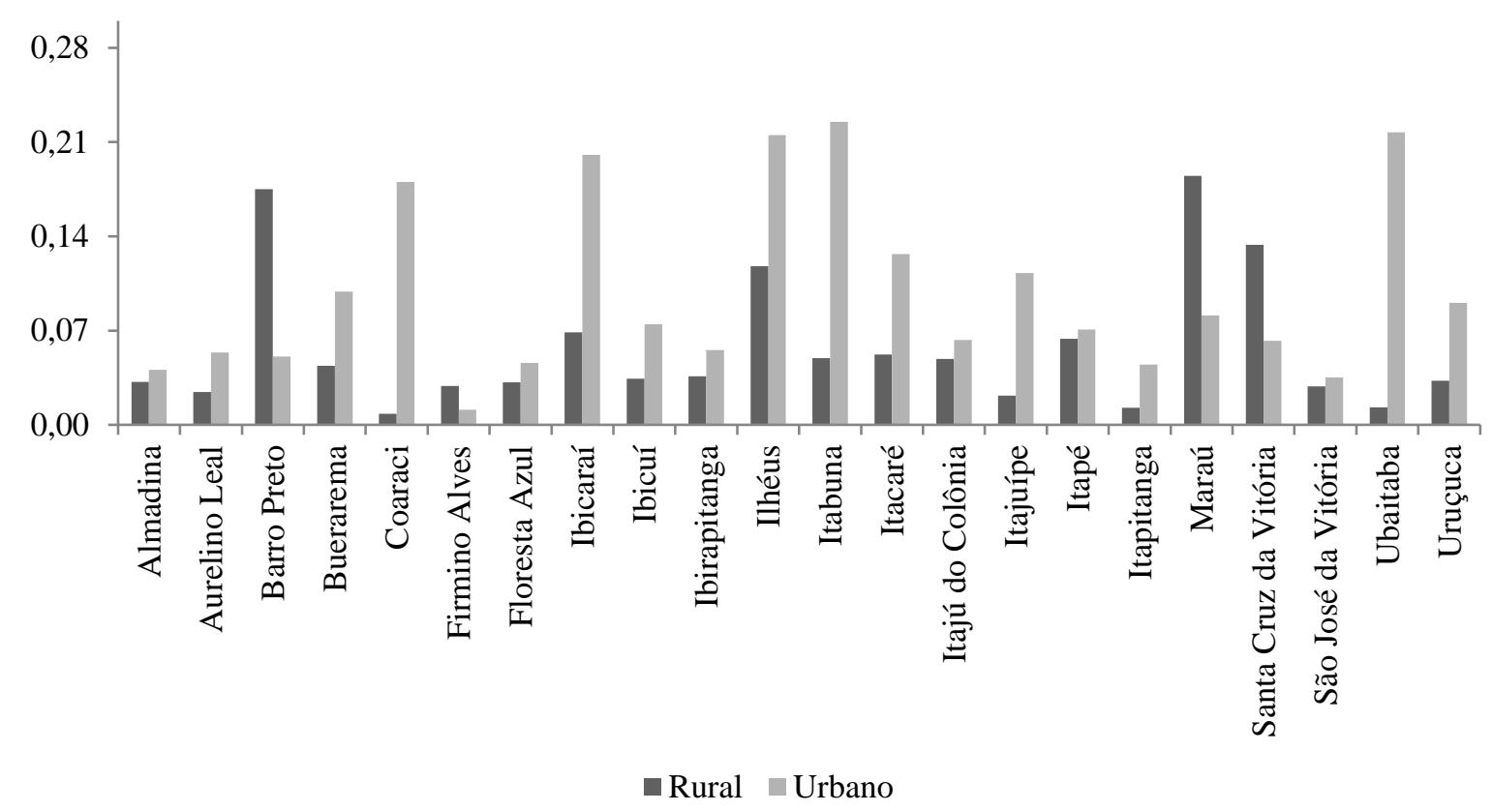

Fonte: Elaborada pelos autores.

Ao observar a renda média dos domicílios das zonas urbanas e rurais dos municípios da RII Ilhéus-Itabuna, nota-se em Itabuna a maior desigualdade de renda por setor censitário para o ano de 2010, com valor de $\mathrm{R} \$ 2.975,79$ e $\mathrm{R} \$ 122,97$ respectivamente. A seguir, demonstramos na Figura 6 que os demais municípios apresentam fortes disparidades de renda, porém com variação menor entre a renda da zona urbana e rural, demonstrado nas linhas de cor verde e azul.

Figura 6: Renda média dos municípios com maior desigualdade de renda da RII Ilhéus-Itabuna, Bahia, por setor censitário rural e urbano, 2010 (continuação)

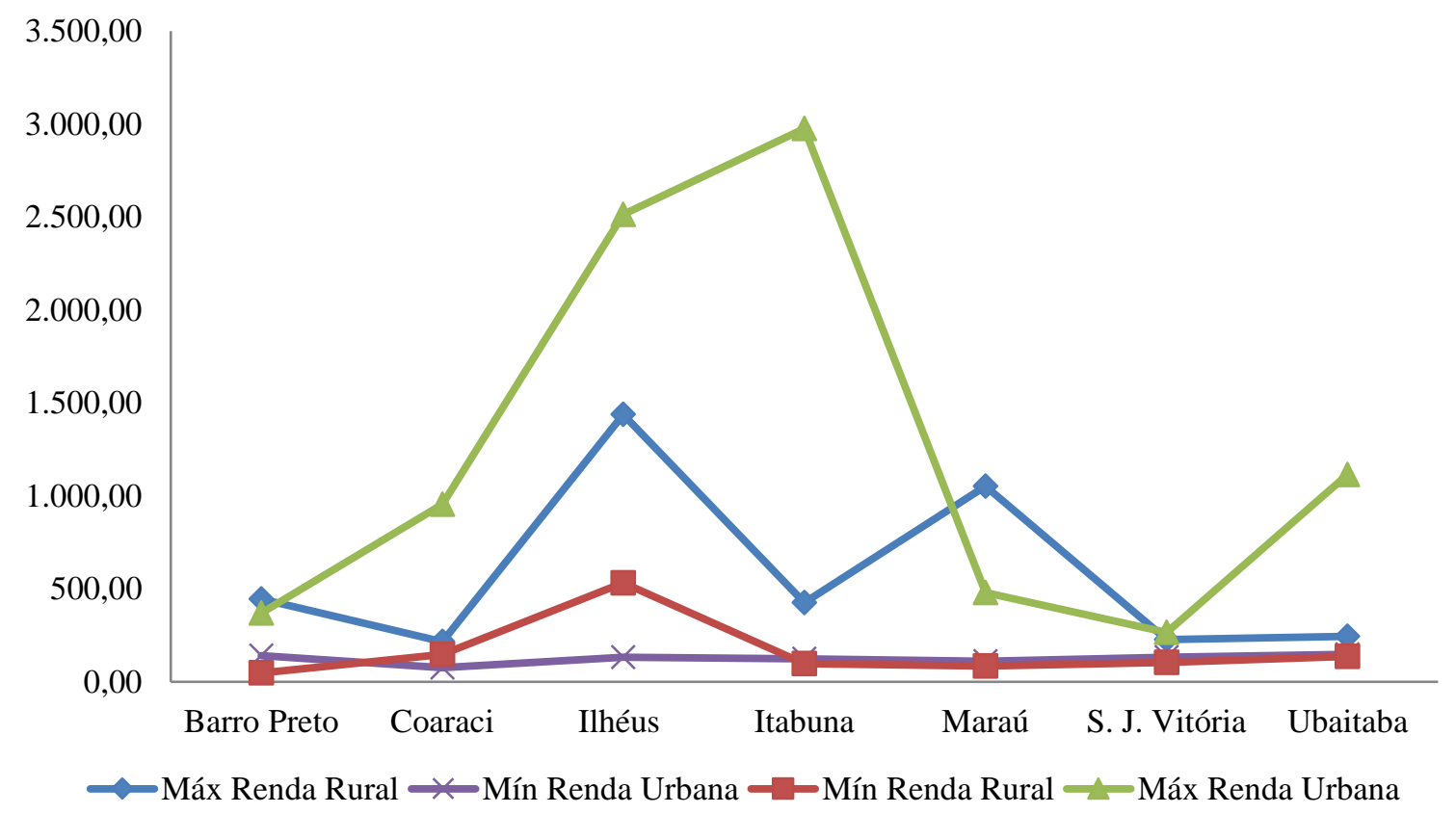

Fonte: Elaborada pelos autores.

O município de Maraú é predominantemente rural ( 7 setores censitários urbanos e 43 setores censitários rurais), e dentre aqueles caracteristicamente rurais dos que compõem a região de estudo, apresenta a maior desigualdade de renda regional. 
Esses resultados refletem a heterogeneidade da região estudada e, consequentemente, a necessidade de se delinear políticas públicas que permitam aumentar a capacidade da população na aquisição de ativos, o que contribuiria para reduzir essa forte heterogeneidade regional.

\section{Pobreza sob a ótica multidimensional}

A pobreza encontra-se espraiada na Região de Influência Imediata Ilhéus-Itabuna, em que a média do IPM nos setores censitários urbanos foi de 0,30 , e no rural foi 0,54 . Porém, tal fenômeno se manifesta de maneira distinta, pois enquanto o IPM varia entre 0,25 e 0,50 para os setores censitários urbanos, nos setores censitários rurais os valores situam-se entre 0,50 e 0,75. Tais valores espelham a elevada pobreza nessa região. Os setores censitários rurais em sua maioria (67\%) configuram-se como pobres, pois o valor do IPM encontra-se acima de 0,50 (Figura 7), enquanto nos urbanos esse percentual é de apenas 2,1\% para essa faixa de IPM.

Dentre os indicadores que compõem o IPM, aqueles que apresentam maiores privações percentuais por habitantes são a capacidade de aquisição de ativos e de se alimentar, os quais estão diretamente relacionados à renda da população. Subjacente a esses, têm-se também os indicadores relacionados à infraestrutura básica (esgotamento sanitário) e educação.

Itabuna e Ilhéus são os municípios mais urbanizados da RII Ilhéus-Itabuna, com taxa de urbanização de $98 \%$ e $85 \%$, respectivamente. Nesses municípios a pobreza multidimensional é menor em relação à média da região, enquanto em Itabuna e Ilhéus o IPM é 0,22 e 0,32, respectivamente, a média da região é 0,41 .

Nota-se que há uma relação inversa entre o grau de urbanização do município e o IPM, pois os menores valores do IPM estão presentes nos locais mais urbanizados. Tal fato decorre porque há vantagens comparativas em relação à produção e oferta de inúmeros bens e serviços na presença de maiores aglomerações urbanas, resultando em economias de aglomeração e de escala, possibilitando também melhores oportunidades de renda e emprego para a população, pois isso se constitui em fator de atração de mão de obra e investimentos, os quais pressionam a oferta por melhores condições de saneamento básico, abastecimento de água, energia elétrica, capacidade de se alimentar e adquirir ativos. Nota-se ainda que, na maioria dos setores censitários de Itabuna e Ilhéus, o IPM situou-se na faixa de 0,01 - 0,25. A Figura 8 mostra que nas áreas rurais dos municípios de Itabuna e Ilhéus o IPM é mais elevado (entre 0,50 - 0,75), enquanto nas áreas urbanas o IPM situase entre $0,01-0,25$ e $0,25-0,50$, respectivamente, evidenciando a presença de desigualdade internas nesses municípios.

Figura 7: Índice de Pobreza Multidimensional, RII Ilhéus-Itabuna por setor censitário, 2010

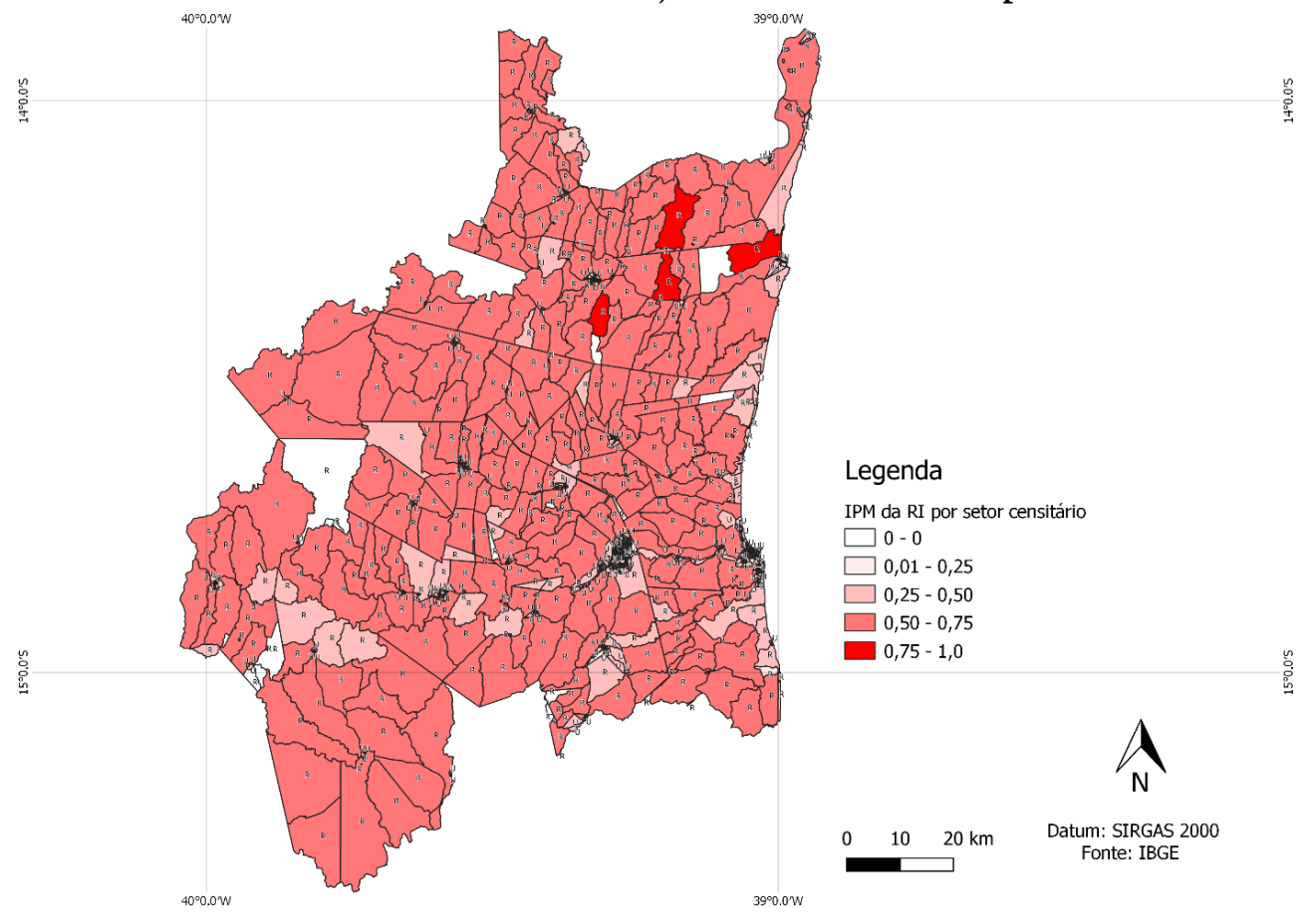


Nota: os setores censitários rurais estão representados pela letra " $R$ ”, os urbanos podem ser visualizados pelo aglomerado de linhas, já que seus polígonos não são visíveis no mapa e são representados pela letra "U”. A coloração branca representa ausência de informação do setor. Fonte: Elaborada pelos autores.

Essas disparidades associam-se desde o processo de formação econômica das cidades, até sua urbanização. No caso específico de Ilhéus e Itabuna, a produção de cacau na década de 1990 gerou influência na configuração das cidades produtoras dessa fruta. A infraestrutura advinda da produção cacaueira, somada à localização privilegiadas de Ilhéus e Itabuna, contribuiu que se conformassem como cidades médias, as quais têm papel relevante nas economias das cidades circunvizinhas. Complementarmente, a crise do cacau gerou êxodo rural e concentração das populações nas áreas urbanas nas cidades centro da RII analisada, especialmente nas zonas periféricas, as quais não estavam preparadas para receber esses migrantes. Assim, os resultados do IPM evidenciam esse processo de pobreza e suas distinções entre as zonas rurais e urbanas, conforme salientado em Martins (2018).

Figura 8: Índice de Pobreza Multidimensional nos municípios de Ilhéus e Itabuna por setor censitário, 2010
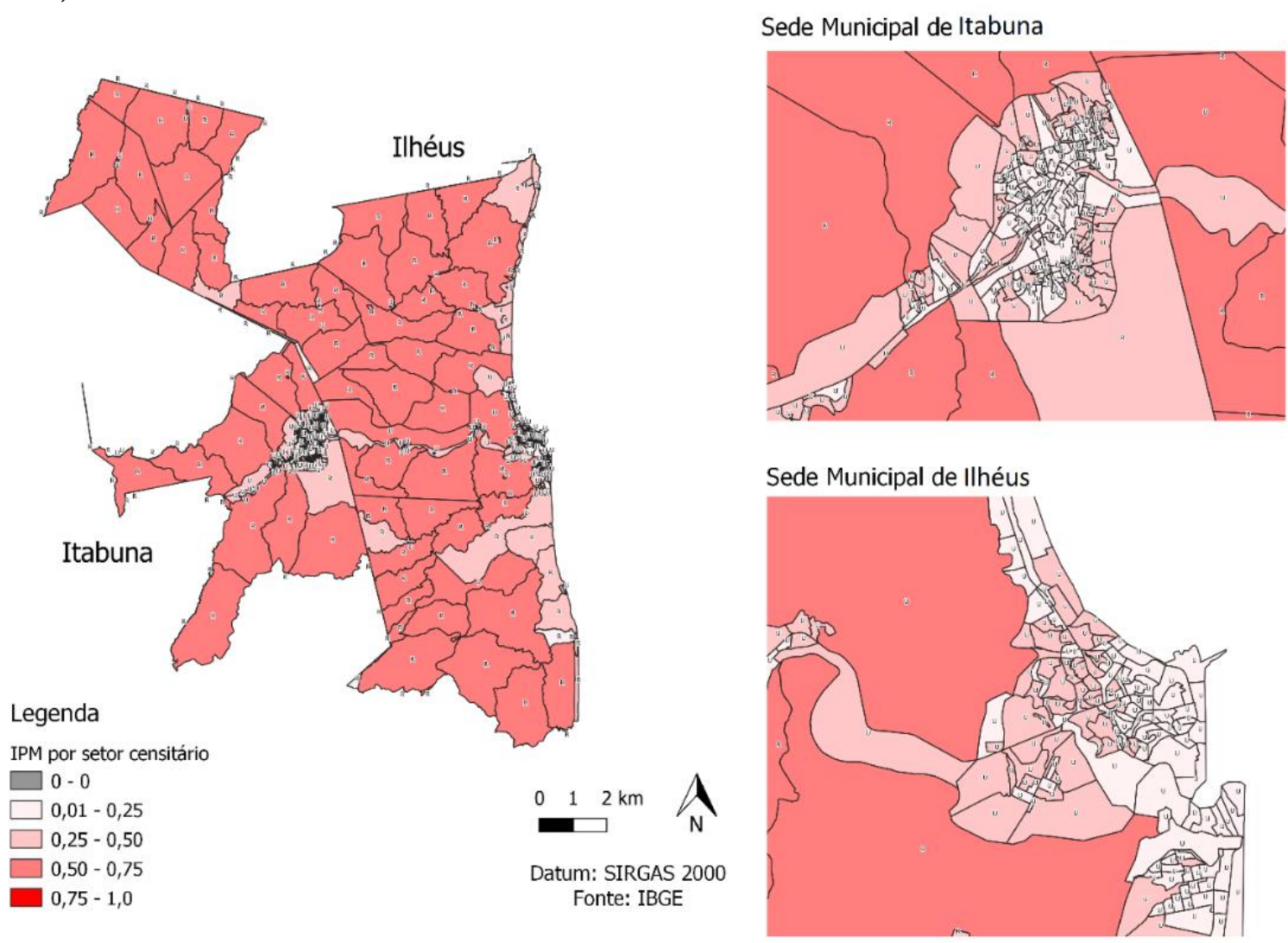

Fonte: Elaborada pelos autores.

Outros municípios, como Coaraci, que tem a terceira maior população urbana, e Ibirapitanga, a segunda maior população rural, seguem essa mesma dinâmica, com IPM menor para os setores censitários urbanos comparativamente aos rurais (Tabela 3): 
Tabela 3: Média do IPM nos setores censitários rurais e urbanos na RII Ilhéus-Itabuna, 2010

\begin{tabular}{lll}
\hline Município & Média IPM (Rural) & Média IPM (Urbano) \\
\hline Almadina & 0,57 & 0,29 \\
Aurelino Leal & 0,58 & 0,39 \\
Barro Preto & 0,57 & 0,32 \\
Buerarema & 0,55 & 0,32 \\
Coaraci & 0,58 & 0,28 \\
Firmino Alves & 0,43 & 0,31 \\
Floresta Azul & 0,58 & 0,27 \\
Ibicaraí & 0,47 & 0,29 \\
Ibicuí & 0,56 & 0,32 \\
Ibirapitanga & 0,52 & 0,35 \\
Ilhéus & 0,48 & 0,24 \\
Itabuna & 0,53 & 0,21 \\
Itacaré & 0,67 & 0,21 \\
Itaju do Colônia & 0,60 & 0,34 \\
Itajuípe & 0,56 & 0,26 \\
Itapé & 0,53 & 0,33 \\
Itapitanga & 0,57 & 0,31 \\
Maraú & 0,52 & 0,37 \\
Santa Cruz da Vitória & 0,51 & 0,27 \\
São José da Vitória & 0,59 & 0,37 \\
Ubaitaba & 0,57 & 0,30 \\
Uruçuca & 0,56 & 0,30 \\
\hline Total & 0,54 & 0,30 \\
\hline & & \\
& & Fonte: Elaborada pelos autores.
\end{tabular}

Pode-se constatar que os valores médios do IPM por setores censitários revelam heterogeneidades intra e inter-regional da área estudada, em que Ilhéus e Itabuna se destacam com os menores IPM para as áreas urbanas, e Aurelino Leal e São José da Vitória apresentam os maiores valores de IPM. Em relação à pobreza rural, esta é mais evidente, na região de estudo, nos municípios de Itaju do Colônia e Itacaré.

\section{Considerações finais}

Nota-se que a região é predominantemente urbana, pois há uma concentração populacional nos setores censitários urbanos. Tal situação reflete o processo de êxodo rural, especialmente em função do declínio da lavoura cacaueira, mas também do processo de urbanização "acelerado" da região que passou a se especializar na oferta de serviços.

Independentemente do indicador utilizado, neste trabalho, nota-se que a região apresenta fortes desigualdades de renda, as quais são mais evidentes nos municípios-centro da região, Ilhéus e Itabuna. A pobreza está espraiada por toda a região, apresentando-se com menor intensidade, normalmente nas áreas urbanas, e de forma mais acentuada nas áreas rurais da região.

Os elevados níveis de privação em relação à aquisição de ativos e saneamento sugerem políticas de fomento ao emprego para a população em idade economicamente ativa, a partir de instrumentos que melhorem a distribuição de renda. Em toda a extensão rural da região, há carência na oferta de serviços de saúde básica e na oferta de serviços de fornecimento de água e saneamento.

Sob essa condição, vislumbra-se para a necessidade de uma agenda pública pautada em instrumentos que atenuem os problemas relacionados à pobreza, a fim de corrigir as graves disparidades internas regionais.

\section{Referências}


ALKIRE, S., FOSTER, J. Counting and Multidimensional Poverty Measurement. OPHI, 2009. working paper $\mathrm{n}^{\circ} 32$. Disponível em: http://www.ophi.org.uk/wp-content/uploads/OPHI-wp32.pdf. Acesso em: 29 out. 2018.

ALKIRE, S., FOSTER, J. Counting and Multidimensional Poverty Measurement. OPHI, 2007 (Revised May 2008). Working paper $\mathrm{n}^{\circ}$ 7. Disponível em: www. http://www.ophi.org.uk/wpcontent/uploads/ophi-wp7.pdf. Acesso em: 29 out. 2018.

ALKIRE, S., SANTOS, M. E. Acute Multidimensional Poverty: A New Index for Developing Countries. OPHI, 2010. Working paper $\mathrm{n}^{\circ}$ 38. Disponível em: http://www.ophi.org.uk/wpcontent/uploads/ophi-wp38.pdf. Acesso em: 29 out. 2018.

ALKIRE. S. Dimensions of human development. World Development. England: vol. 30, n. 2, p.181205, 2002.

BARROS, R. P. de; HENRIQUES, R.; MENDONÇA, R. Desigualdade e pobreza no Brasil: a estabilidade inaceitável. In: HENIQUES, R. (Ed.). Desigualdade e pobreza no Brasil. Rio de Janeiro: Ipea, 2000.

BARROS, R. P.; CARVALHO. M.; FRANCO. S. Pobreza multidimensional no Brasil. In: BARROS, R. P. (ORG); FOGUEL, M. N. (ORG); ULYSSEA, G (ORG). Desigualdade de renda no Brasil: uma análise de queda recente. Brasília: IPEA, 2006.

CAVALCANTI, D. M., SILVA, J. L. M., QUEIROZ, M. F. M. Hiato de renda urbano e rural na bahia: uma análise do período de 2001 a 2009. VIII Encontro de Economia Baiana - SET. 2012. Disponível em: http://www.eeb.sei.ba.gov.br/pdf/2012/eb/hiato_de_renda.pdf. Acesso em: 20 jul. 2019.

DEDECCA, C. S. A redução da Desigualdade no Brasil: uma estratégica complexa. In: BARROS, R. P. (ORG); FOGUEL, M. N. (ORG); ULYSSEA, G (ORG). Desigualdade de renda no Brasil: uma análise de queda recente. Brasília: IPEA, 2006.

GIL, A. C. Métodos e técnicas de pesquisa social. 6 ed - São Paulo: Atlas, 2008.

GUERRA, O. Bahia: liderança econômica regional e desigualdade social. Bahia anál. dados, Salvador, v.27, n.2, p.55-85, jul.-dez. 2017.

IBGE. Divisão Regional do Brasil em regiões Imediatas e regiões geográficas Intermediárias: 2017. Coordenação de Geografia. Rio de Janeiro, IBGE, 2017, 82p. ISBN: 978-85-240-4418-2.

. Cidades, 2019. Disponível em: https://cidades.ibge.gov.br/. Acesso em: 23 maio 2019.

Divisão
$\overline{\text { https://ia600603.us.archive.org/2/items/RegiesGeogrrficasBrasil2017/Regi\%C3\%B5es\%20geogr\%C }}$
3\%A1ficas_Brasil\%202017.pdf. Acesso em: 23 maio 2019.

IPEA. Atlas da violência 2018: políticas públicas e retratos dos municípios brasileiros. Disponível em: $\quad$ http://www.ipea.gov.br/atlasviolencia/arquivos/downloads/3059-2049-7208180614atlas2018retratosdosmunicipios-1.pdf. Acesso 21 jul. 2019.

LEITE, R. A.; SILVA, A. F.; ARAUJO, J. A.; SEIXAS, G. U. Pobreza multidimensional no estado da Bahia com enfoque no meio rural utilizando a abordagem de Bourguignon e Chakravarty. Nexos Econômicos, Salvador, v. 10, n. 1, p.7-32, 2016.

MARTINS, H. M. de O. ANÁLISE DA ESPACIALIDADE DA POBREZA MULTIDIMENSIONAL NOS MUNICÍPIOS DE ITABUNA E ILHÉUS A PARTIR DOS SETORES CENSITÁRIOS. 2018. 101 f. Dissertação (Mestrado em Economia Regional e Políticas Públicas) - Universidade Estadual de Santa Cruz, Ilhéus, 2018. 
NERI, M. C.; CONSIDERA, C. P. Crescimento, desigualdade e pobreza: o impacto da estabilização. Economia Brasileira em Perspectiva, Rio de Janeiro: Ipea, v. 1, p. 49-82, 1996.

NERI, M. Desigualdade, Estabilidade e Bem-Estar Social. In: BARROS, R. P. (ORG); FOGUEL, M. N. (ORG); ULYSSEA, G (ORG). Desigualdade de renda no Brasil: uma análise de queda recente. Brasília: IPEA, 2006.

OLIVEIRA, R. C.; CAVALCANTI. F. L. Nível e evolução da desigualdade de renda na Bahia: uma avaliação do papel da educação e dos programas sociais. IX Encontro de Economia Baiana - SET. 2013. Disponível em: http://www.eeb.sei.ba.gov.br/pdf/2013/eb/nivel_e_evolucao.pdf. Acesso em: 25 jul. 2019.

OXFAM BRASIL. PAÍS ESTAGNADO: UM RETRATO DAS DESIGUALDADES BRASILEIRAS. Org: Rafael Borges e Katia Maia. Revisão: Wand Brant. Editora Brief Comunicação, 2018. Disponível em:

https://www.oxfam.org.br/sites/default/files/arquivos/relatorio_desigualdade_2018_pais_estagnado _digital.pdf. Acesso em: 25 jul. 2019.

PIRES, M. de M., MOROLlÓN, F. R., GOMES, A. da S., POLĖSE, M. ECONOMIA URBANA E REGIONAL: território, cidade e desenvolvimento. Ilhéus, BA: Editus, 2018.

PRATES, E. M. POBREZA NOS TERRITÓRIOS DE IDENTIDADE DA BAHIA: uma análise a partir da abordagem multidimensional. 2016.125 f. Dissertação (Mestrado em Economia Regional e Políticas Públicas) - Universidade Estadual de Santa Cruz, Ilhéus, 2016.

ROCHA, S. Pobreza no Brasil: afinal, de que se trata? Rio de Janeiro: FGV Editora, 2003.

SANTOS, A. A. P. dos.; GUIRRA, G. C. S.; SOUZA, L. E. de. Desigualdade, vulnerabilidade social e ampliação da violência homicida em cidades médias do Brasil: um estudo de caso de Itabuna e Ilhéus. In: Informe Geográfico, Ano 10, nº 20, nov/dez 2010. ISSN 1982-8039.

SEN, A. Desenvolvimento como Liberdade. Tradução Laura Teixeira Mota. São Paulo: Editora Schwarcz LTDA, 2010.

SEPLAN, Secretaria de Planejamento. Cenários Prospectivos para a Bahia 2015-2030. Salvador, 2016. Disponível em: http://www.seplan.ba.gov.br. Acesso em: 24 maio 2019.

WILLIAMSON, J. Desigualdade regional e o processo de desenvolvimento nacional: descrição dos padrões. In: SCHWARTZMAN, J. (Org.) Economia regional: textos escolhidos. Belo Horizonte: Editora UFMG, 1977. p. 53 - 116.

WORD INEQUALITY DATABASE. Participação do top 1\% na receita tributária 2001 - 2015. Disponível em: https://wid.world/es/country/es-brazil/. Acesso em: 22 maio 2019. 